\title{
Practical Application of an Electric Field Screen to an Exclusion of Flying Insect Pests and Airborne Fungal Conidia from Greenhouses with a Good Air Penetration
}

\author{
K. Kakutani \\ Pharmaceutical Research \& Technology Institute, Kinki University \\ 3-4-1 Kowakae, Osaka 577-8502, Japan \\ Tel: 81-6-6721-2332Ｅ-mail: kakutani@msa.kindai.ac.jp \\ Y. Matsuda (Corresponding author), T. Nonomura \& H. Toyoda \\ Laboratory of Phytoprotection Science \& Technology \\ Faculty of Agriculture, Kinki University, 3327-204 Nara 631-8505, Japan \\ Tel: 81-742-43-5223Ｅ-mail: ymatsuda@nara.kindai.ac.jp \\ J. Kimbara \\ Research Institute, Kagome Co., Ltd., Tochigi 329-2762, Japan \\ Tel: 81-287-36-2935Ｅ-mail: Junji_Kimbara@kagome.co.jp
}

K. Osamura

Technical Development unit, Panasonic Environmental Systems \& Engineering Co., Ltd.

Osaka 564-0062, Japan

Tel: 81-50-3787-2295Ｅ-mail: osamura.kazumi@jp.panasonic.com

\author{
S. Kusakari \\ Agricultural, Food \& Environmental Sciences Research Center of Osaka Prefecture \\ Osaka 583-0862, Japan \\ Tel: 81-729-58-6551Ｅ-mail: kusakari@mbox.epcc.pref.osaka.jp
}

Received: November 21, 2011

Accepted: December 15, $2011 \quad$ Online Published: April 1, 2012

doi:10.5539/jas.v4n5p51

URL: http://dx.doi.org/10.5539/jas.v4n5p51

\begin{abstract}
In an attempt to control pathogens and insect pests affecting greenhouse tomatoes, we evaluated an electric field screen to create an airy greenhouse condition that successfully excluded insect vectors (whiteflies, green peach aphids, western flower thrips and shore flies) of pathogens and airborne conidia of tomato powdery mildew. The screen consisted of three parts: 1) insulated conductor wires (ICWs) arrayed in parallel at 5-mm intervals, 2) two stainless-steel nets that were grounded and placed on both sides of the ICWs, and 3) a direct current (DC) voltage generator to negatively charge the ICWs. An electric field formed between the negative surface charge of the ICWs and the positive charge on the ICW-side surface of the grounded net. The ICWs captured insects and airborne conidia that entered the field. Insects that contacted the outer surface of the screen net avoided the electric field and flew away from the screen. During continuous 3-month greenhouse operation, the screen was durable and functional in exerting stable pest exclusion and good air penetration for ventilation under changing greenhouse climate conditions. In three experiments examining the occurrence of powdery mildew in
\end{abstract}


hydroponically cultured tomato plants on either side of a greenhouse partition, the screen-guarded plants remained germ free throughout the culture period ( 1 month), whereas powdery mildew was present on the leaves of almost all unguarded tomato plants. Thus, our electric field screen provided an airy condition for tomatoes in an open-window greenhouse that successfully excluded airborne pathogens and flying insect pests.

Keywords: Physical control, Hydroponic tomato, Whitefly, Green peach aphid, Western flower thrips, Shore fly, Tomato powdery mildew

\section{A List of Abbreviations}

ICWs, Insulated conductor wires

DC, Direct current

TYLCV, Tomato yellow leaf curl virus

CMV, Cucumber mosaic virus

TSWV, Tomato spotted wilt virus

\section{Introduction}

Hydroponic tomato culture is conducted year-round in the greenhouses of Nara Prefecture, Japan, and tomato plants frequently suffer from pathogen infection and/or insect attack. Infection with insect-carried viruses causes severe damage to tomato plants. Tomato yellow leaf curl virus (TYLCV), carried by the whitefly, Bemisia tabaci (Gennadius), has represented the most serious threat in high-temperature seasons (Tanaka et al., 2008). Cucumber mosaic virus (CMV), carried by the green peach aphid, Myzus persicae (Sulzer) and tomato spotted wilt virus (TSWV), carried by western flower thrips, Frankliniella occidentalis (Pergande) have also occurred frequently in the past 5 years. In addition, shore flies, Scatella stagnalis (Falle'n) which inhabit and multiply on alga lawns in sponge cubes soaked with hydroponic culture solution, have been found to transmit rhizosphere pathogens, such as Verticillium wilt, Verticillium dahliae and Fusarium crown and root rot, Fusarium oxysporum f. sp. radicis-lycopersici (Gillespie \& Menzies, 1993; El-Hamalawi, 2008). Airborne conidia of fungal pathogens have posed an additional threat. Powdery mildew, Oidium neolycopersici, grey mould, Botrytis cinerea and leaf mould, Fulvia fulva have also occurred commonly on greenhouse tomatoes in the Nara area. Greenhouse tomatoes have been especially affected by year-round powdery mildew infection (Nonomura et al., 2008).

The incessant invasion of these pathogen-transmitting insects and fungal conidia necessitates an efficient protection strategy that addresses a wide range of pests and pathogens entering the greenhouse. To solve this problem, our laboratory developed an electrostatic insect-exclusion technique. This electrostatic method was devised initially to collect mature conidia on conidiophores of powdery mildews (Moriura et al., 2006a, 2006b; Nonomura et al., 2009). It has been further developed as a spore-precipitation screen for tomato powdery mildew (Matsuda et al., 2006; Shimizu et al., 2007) and an insect-exclusion screen for whiteflies (Tanaka et al., 2008), cigarette beetles, and vinegar flies (a warehouse pest) (Matsuda et al., 2011). The first electrostatic spore precipitator was a screen that created a non-uniform electric field around insulated copper conductor wires arranged in parallel (Matsuda et al., 2006). The electric field generated an electrostatic force that attracted fungal conidia entering the field. Unfortunately, the spore precipitator was ineffective in trapping some of the primary greenhouse insect species. The second device addressed this problem with a dielectric screen, in which paired insulator cylinders were arranged in parallel and oppositely charged with equal magnitude using two electrostatic voltage generators (Tanaka et al., 2008). This type of screen utilised electric lines of force that moved a positively charged particle from the positive to the negative pole (Griffith, 2004; Halliday et al., 2005). The force was sufficiently strong to capture adult whiteflies, but the screen was ineffective in capturing larger insects with the strength to escape the screen trap. The third device was a triple-layered electric field screen, in which grounded metal nets were placed on both sides of the original spore precipitator to create dielectric poles (Matsuda et al., 2011). This screen captured larger insects (2-4-mm body length) and may also be applicable for greenhouse insect pests with body sizes ranging from $0.8 \mathrm{~mm}$ (whiteflies) to $4 \mathrm{~mm}$ (shore flies). Because the screen is an improved version of the original spore precipitator, we also expected it to capture airborne conidia.

In the present study, we constructed a weatherproof electric field screen that was practical for long-term operation and created an airy, pest- and spore-free space for tomatoes in open-window greenhouses.

\section{Materials and Methods}

\subsection{Electric Field Screen}

Figure 1 presents a diagram of the triple-layered electric field screen. The screen consisted of 180 insulated iron conductor wires and two stainless-steel nets. An iron wire (2-mm diameter, 90-cm length) was passed through a 
transparent vinyl-chloride insulator sleeve (1-mm thickness) to create an insulated conductor wire (ICW). ICWs were arrayed in parallel at $5-\mathrm{mm}$ intervals and linked to one another and to the connector terminal of an electrostatic direct current (DC) voltage generator. Two stainless-steel nets (1.6-mm mesh) on an aluminium window frame were grounded and placed $3 \mathrm{~mm}$ from each side of the ICW layer. To waterproof the screen, the generator and the electric wires connecting the ICWs to the generator were placed inside the frame and sealed with silicon resin. The ICWs were negatively charged to dielectrically polarise the ICW insulator sleeve; the outer surface was negatively charged and the inner conductor-wire surface was positively charged (Matsuda et al., 2006). The negative surface charge of the ICWs polarised (electrostatically induced) the grounded nets (conductor), creating the opposite surface charge on the ICW-side net surfaces. These opposite charges acted as dielectric poles to form an electric field between the ICW and the grounded nets (Matsuda et al., 2011).

\subsection{Insect Pests}

The present study used adults of four insect species: whiteflies, B. tabaci, type B, green peach aphids, $M$. persicae, western flower thrips, F. occidentalis and shore flies, S. stagnalis. Whiteflies were reared on 10-day-old kidney-bean, Phaseolus vulgaris L. 'Nagauzura-saitou' seedlings (Tanaka et al., 2008). Male and female adults were collected using an insect aspirator (Wildlife Supply Company, Buffalo, NY, USA). Adult western flower thrips and wingless adult female green peach aphids were purchased from Sumika Technoservice (Hyogo, Japan) and reared on water-swollen seeds and 1-week-old broad-bean, Vicia faba L. 'GB-Blend' seedlings, according to the methods of Murai (1991) and Murai \& Loomans (2001), respectively. Hatched winged adult female green peach aphids and adult male and female western flower thrips were collected with an insect aspirator and used for the following experiments. Adult shore flies were collected from a hydroponic tomato greenhouse and maintained on a lawn of green algae (Chlamydomonas reinhardtii Dangeard). This lawn had been cultured on a sponge cube soaked in hydroponic culture solution in a transparent $2 \mathrm{~L}$ culture bottle; the bottle opening was covered with a woven net of $0.6-\mathrm{mm}$ mesh (Nonomura et al., 2001). The test insects were held in a temperature-controlled growth chamber $\left(26 \pm 2^{\circ} \mathrm{C}, 35-45 \%\right.$ relative humidity, 16 -h photoperiod with 4000 lux from fluorescent lamps). Average body sizes (length from head to wing tip) of the test insects (20 adults of each species) were $0.78 \pm 0.09 \mathrm{~mm}$ in whiteflies, $3.75 \pm 0.27 \mathrm{~mm}$ in green peach aphids, $1.46 \pm 0.13 \mathrm{~mm}$ in western flower thrips, and $3.83 \pm 0.37 \mathrm{~mm}$ in shore flies.

\subsection{Assay for Insect Capture and Avoidance}

The screen was installed on the window of an A-frame greenhouse (Figure 2A, B) and negatively charged with different voltages $(1-5 \mathrm{kV})$. To determine the voltage that captured all test insects, adult insects were blown into the space between the ICWs and the net with an insect aspirator. A blower (max. wind speed: $7 \mathrm{~m} \mathrm{~s}^{-1}$ at screen net) was directed at the captured insects for $10 \mathrm{~min}$. Twenty adults were used for each test insect and voltage. The experiments were repeated three times and data are presented as means and standard deviations of these three replications.

To test insect avoidance, we constructed a transparent acrylic cylinder (40-cm length, $30-\mathrm{cm}$ diameter) with an electric fan at one end (Figure 2C). The open end of the cylinder was placed against the screen net and adult test insects were released inside the cylinder. The first experiment was conducted under a windless condition because all insects remained motionless on the cylinder wall when they were subjected to air currents exceeding $0.5 \mathrm{~m} \mathrm{~s}^{-1}$. In the second experiment, the insects were released and then blown with an electric fan at different wind speeds (0.5-5 $\mathrm{m} \mathrm{s}^{-1}$ at screen net) when they reached the outer screen surface. In both tests, insects were classified according to three action types: A) passing through the screen, B) leaving the net without entering the screen, and C) being drawn inside the screen and captured with the ICWs. Twenty insects were used for each voltage. The experiments were repeated three times and data are presented as means and standard deviations of these three replications.

\subsection{Screen Durability and Functionability in a Long-period Operation}

A greenhouse $\left(20 \times 8 \mathrm{~m}^{2}\right)$ was divided into two sections with a partition, and screens were mounted on all windows along two sides of one section. The screens were negatively charged $(4.2 \mathrm{kV})$ and operated continuously for 3 months. The roof windows of the screened section were closed (screens were not installed on roof windows due to structural difficulty), and the section was ventilated with a ceiling-mounted air-circulating fan and a ventilator at the front of the greenhouse. The unscreened section was ventilated by an updraft from the laterally and roof opened windows. Temperature changes were monitored daily at 30 points in each section using thermometer data loggers. To examine whether the screens retained their insect-capturing ability during long-term operation, we blew adult test insects inside the screen at 10-day intervals for 3 months. At the end of the experiment, the screens were detached and examined to detect warping or cracking of screen components. 


\subsection{Protection of Greenhouse Tomatoes from Powdery Mildew Infection}

Screens were installed on all lateral windows in both sections of the partitioned greenhouse. Each section was ventilated with fans, as described earlier. The screens in one section were negatively charged $(4.2 \mathrm{kV})$ and operated continuously for 30 days, while the screens in the other section were not charged as a control. One-month-old tomato (Lycopersicon esculentum Mill, 'Micro-Tom') seedlings were transferred to hydroponic troughs in both sections to examine the occurrence of powdery-mildew colonies on leaves. The 'Micro-Tom' variety was selected for this study because it is highly susceptible to tomato powdery mildew (Matsuda et al., 2005). The plants were hydroponically cultured according to previously described methods (Nonomura et al., 2001). To avoid secondary infection with progeny conidia, powdery-mildew colonies on leaves were destroyed when they first became visible (preceding conidial production by conidiophores). For this purpose, we used a cylindrical electrostatic discharge generator according to a previously described method (Nonomura et al., 2008); we brought the pointed tip of the 30-kV-charged copper needle of a discharge generator within $25 \mathrm{~mm}$ of the leaf and exposed the colony to a 5-s corona discharge. Exposure sites were suberised within 1 day after exposure and thus appeared as brownish-grey spots (suberin spots) at the leaf colony sites. These spots were counted every 10 days for 30 days to determine the number of conidia forming the colonies. The experiments were repeated three times.

\section{Results}

In the first experiment, we sought to determine the optimal voltage for achieving a $100 \%$ capture rate of test insects that were blown into the space between the ICWs and the net with an insect aspirator (Table 1). The attractive force of the screen increased in direct proportion to an increase in voltage applied to the ICWs. All insects that entered the electric field were turned on their backs, and their wings were captured with the ICWs. Voltages achieving $100 \%$ capture rates varied among the test insects; higher voltages were necessary to capture larger insects with the strength to escape the screen trap. The 4.2-kV-charged screen captured all insect pests with body sizes ranging from $0.8 \mathrm{~mm}$ (whiteflies) to $4 \mathrm{~mm}$ (shore flies). We also confirmed that the screen was able to capture insects at a wind speed of $7 \mathrm{~m} \mathrm{~s}^{-1}$ (Table 1). We thus used a screen with a negative 4.2-kV charge for all subsequent experiments.

In the second experiment, we examined whether test insects avoided entering the screen when they reached the screen net (Figure 3). When the screen was not charged, insects stayed or walked on it for a short period (2-5 s) and then passed through the screen. In contrast, insects on the net of the charged screen placed their antennae inside the screen and then flew away without entering the screen, indicating that the insects recognised the electric field with their antennae and avoided entrance. The strong attraction of the ICW drew some insects inside the screen when they probed it with their antennae. This compulsory attraction was more frequent when the insects were subjected to wind $\left(<0.5 \mathrm{~m} \mathrm{~s}^{-1}\right)$. Importantly, the screen was able to capture all insects when they were pushed inside the screen at the maximum wind speed $\left(5 \mathrm{~m} \mathrm{~s}^{-1}\right.$; Figure 3$)$.

Before the practical application of the screen in greenhouse tomato cultivation, we tested screens installed on greenhouse windows to address several factors during continuous 3-month operation: greenhouse temperature improvement, and stable functionality and weather resistance of the screen. Temperature ranges at points 1,2 , and $3 \mathrm{~m}$ from the floor in screened/unscreened greenhouse sections were $25.1-34.5 / 24.0-34.0^{\circ} \mathrm{C}$, $25.1-37.0 / 25.0-36.8^{\circ} \mathrm{C}$, and $25.6-40.1 / 25.0-39.1^{\circ} \mathrm{C}$, respectively, indicating that the screened section maintained the same temperatures as in the unscreened section with open windows. All window-mounted screens captured all insects in all blowing trials, indicating that the screen functioned normally throughout the continuous long-term operation. Examination of the screen components at the end of the experiment confirmed that the uniform distance between the ICWs and the nets was retained after 3 months of operation. We found no change in the shape of ICWs or stainless-steel nets related to high summer temperatures or direct sunlight. Moreover, no distortion or degradation was detected in the insulator sleeves used to cover the ICWs. The screen was waterproofed by sealing the frame with silicon resin to prevent the entrance of rain and dew. The sleeve surface was very hydrophobic, preventing water droplets from remaining on the ICWs. The screen thus functioned during rain and could be washed with a jet of water after use.

We conducted a practical greenhouse experiment with the aim of excluding windborne conidia of tomato powdery mildew (Table 2). The occurrence of powdery mildew was constant in the unscreened greenhouse section in three experiments. In contrast, no powdery-mildew colony was detected in the screened section in any experiments, indicating that the screen was highly effective in excluding airborne conidia of the pathogen. 


\section{Discussion}

Our long-standing goal in greenhouse tomato production and protection is to integrate physical methods in measures to control pathogens and pests, thereby reducing the use of agrochemicals such as fungicides and insecticides. A woven insect-proof screen has been conventionally used to impede the entrance of insects into greenhouses (Teitel et al., 1999). However, the TYLCV epidemic in greenhouse tomatoes required the use of fine (0.3-0.4-mm mesh) insect-proof screens to prevent vector whiteflies from entering greenhouses (Taylor et al., 2001). The disadvantage of this fine-mesh screening was an excessive reduction in ventilation that caused overheating and increased relative humidity (Weintraub \& Berlinger, 2004). In comparison, the screen used in the present study allowed better air penetration for ventilation due to the airy side nets. The net mesh size (1.6-mm) was considerably larger than that of conventional woven screens. In the present study, the use of a ventilation fan in the screened greenhouse section allowed us to maintain the same optimal temperature ranges as in the open-window unscreened greenhouse.

Screen durability is a basic requirement to ensure long-term operation under variable climate conditions. Careful scrutiny of the screen components at the end of the experiment revealed no cracking, warping, or distortion. Uniform distance between the ICWs and the nets is essential for electrostatic functionality (Matsuda et al., 2011); we found that this distance was retained after 3 months of operation. Water resistance is vital to avoid electric leakage caused by rainwater. The screen was effectively sealed to prevent the entrance of rain and dew, allowing it to be used on rainy days and washed with a jet of water after use.

The consumption of electricity by the present screen system is an economically important consideration for its practical use. Our screen system had a simple structure consisting of three components: ICWs, grounded nets, and a voltage generator. The voltage generator increased the voltage (from $100 \mathrm{~V}$ to $4.2 \mathrm{kV}$ ) to charge the ICWs. Through electrostatic induction of a conductor in an electric field (Jonassen, 2002), accumulated negative charge in the ICWs created an electric field to polarise the grounded nets (Matsuda et al., 2011). The insulation of the conductor wires suppressed electric current from the charged ICWs to the grounded nets. Because no electric current was generated, the screen consumed no electricity. The 5-watt voltage generator was the only system component requiring an electric power supply, and its electricity consumption was equivalent to that of a small light bulb.

The system was structurally safeguarded by the production of an electric field inside the screen, the insulation of conductor wires, and the use of grounded nets. As mentioned earlier, the electric field formed between the negative charge of the ICWs and the positive charge on the ICW-sides of the nets (Matsuda et al., 2011). The outer net surfaces possessed no charge and were safe to touch. Insulation of the charged ICWs suppressed the electric current through arc discharge (Matsuda et al., 2006, 2011; Tanaka et al., 2008). If an insulator sleeve was to be accidentally broken, the grounded nets would act as a safety device to direct electric current from the charged ICWs to a ground.

The screen demonstrated a strong ability to capture all test insects with different body sizes. The force was sufficiently strong to capture insects on the ICW when the screen was blown at $5 \mathrm{~m} \mathrm{~s}^{-1}$ and to capture insects that pushed inside the screen at a wind speed of $7 \mathrm{~m} \mathrm{~s}^{-1}$. Moreover, the screen retained this ability throughout 3 months of continuous operation under greenhouse conditions, indicating its practical applicability in the protection of greenhouse tomatoes from pests. In addition to capturing insects that entered the screened inner space, the screen repelled insects that reached the outer net surface. As indicated in our previous work (Matsuda et al., 2011), this repellent function was due to avoidance by the insects. All insects were observed to perceive the electric field with their antennae and then fly away from the screen. Thus, these results suggest that the screen could exclude insect pests from the greenhouse by repelling them under a windless condition and by capturing them on a windy day.

Because airborne conidia of fungal pathogens are readily transmitted by wind, conidial invasion was an inevitable threat when greenhouses were covered with a conventional woven insect net of the finest mesh size (Nonomura et al., 2008). The primary purpose of the present study was thus to monitor the screens' ability to successfully exclude airborne conidia of tomato powdery mildew from the greenhouse. Because it was difficult to directly monitor the conidia attracted to screens installed on greenhouse windows, we routinely monitored the appearance of powdery-mildew colonies on leaves of tomato plants cultured in charged and uncharged screened greenhouse sections. Although conidium-forming colonies represented only a portion of the conidia that entered the greenhouse, this method was a useful proxy for the total amount of conidia present. To enhance the reliability of this method, however, it was essential to avoid secondary infection of progeny conidia released from the infected plants. We found that exposure to corona discharge was highly effective in preventing such infection 
because it immediately destroyed superficial hyphae and conidiophores in the colonies (Nonomura et al., 2008). We confirmed the complete suppression of conidium production after the exposure treatment of immature colonies (upon initial visibility). Suberin spots $(6-8-\mathrm{mm}$ diameter) at corona-discharge exposure sites reflected the emergence of powdery-mildew colonies, allowing quantification. The detection of numerous powdery-mildew colonies on tomato leaves in the unguarded greenhouse section strongly suggested that the other section of the same greenhouse also experienced a continuous invasion threat by airborne conidia during the three experimental periods. Tomato plants in the screen-charged section remained uninfected throughout all experimental periods. These results suggest that tomato plants in the screen-charged section were guarded because of the successful capture of conidia by the screens on the windows. The feasibility of the practical use of this screen system should be confirmed in an actual greenhouse assay.

\section{Conclusions}

In this study, we successfully constructed a weatherproof, economical, and environmentally friendly electric field screen that excluded airborne pathogens and insect pests from greenhouses. This screen allowed conidiumand pest-free tomato cultivation in open-window greenhouses with good air penetration and withstood continuous long-term operation.

\section{References}

El-Hamalawi, Z. A. (2008). Attraction, acquisition, retention and spatiotemporal distribution of soilborne plant pathogenic fungi by shore flies. Ann. Appl. Biol., 152, 169-177. http://dx.doi.org/10.1111/j.1744-7348.2007.00191.x

Gillespie, D. R., \& Menzies, J. G. (1993). Fungus gnats vector Fusarium oxysporum f. sp. radicis-lycopersici. Ann. Appl. Biol., 123, 539-544. http://dx.doi.org/10.1111/j.1744-7348.1993.tb04926.x

Griffith, W. T. (2004). Electrostatic Phenomena. in: Bruflodt, D., \& Loehr, B. S., (eds.) The Physics of Everyday Phenomena, a Conceptual Introduction to Physics, McGraw-Hill, New York. pp. 232-252.

Halliday, D., Resnick, R., \& Walker, J. (2005). Electric Fields. in: Johnson, S., \& Ford, E., (eds.) Fundamentals of Physics, John Wiley \& Sons, New York. pp. 580-604.

Jonassen, N. (2002). Fundamental Concepts. in: Electrostatics, Kluwer Academic Publishers, Massachusetts. pp. 3-30.

Matsuda, Y., Ikeda, H., Moriura, N., Tanaka, N., Shimizu, K., Oichi, W., Nonomura, T., Kakutani, K., Kusakari, S., Higashi, K., \& Toyoda, H. (2006). A new spore precipitator with polarized dielectric insulators for physical control of tomato powdery mildew. Phytopathology, 96, 967-974. http://dx.doi.org/10.1094/PHYTO-96-0967

Matsuda, Y., Mori, Y., Sakano, Y., Nishida, M., Tarumoto, K., Nonomura, T., Nishimura, H., Kusakari, S., \& Toyoda, H. (2005). Screening of wild Lycopersicon species for resistance to Japanese isolate of tomato powdery mildew Oidium neolycopersici. Breeding Sci., 55, 355-360. http://dx.doi.org/10.1270/jsbbs.55.355

Matsuda, Y., Nonomura, T., Kakutani, K., Takikawa, Y., Kimbara, J., Kasaishi, Y., Osamura, K., Kusakari, S., \& Toyoda, H. (2011). A newly devised electric field screen for avoidance and capture of cigarette beetles and vinegar flies. Crop Prot., 30, 155-162. http:// dx.doi.org/10.1016/j.cropro.2010.09.001

Moriura, N., Matsuda, Y., Oichi, W., Nakashima, S., Hirai, T., Nonomura, T., Kakutani, K., Kusakari, S., Higashi, K., \& Toyoda, H. (2006a). An apparatus for collecting total conidia of Blumeria graminis f. sp. hordei from leaf colonies using electrostatic attraction. Plant Pathol., 55, 367-374. http://dx.doi.org/10.1111/j.1365-3059.2006.01356.x

Moriura, N., Matsuda, Y., Oichi, W., Nakashima, S., Hirai, T., Sameshima, T., Nonomura, T., Kakutani, K., Kusakari, S., Higashi, K., \& Toyoda, H. (2006b). Consecutive monitoring of lifelong production of conidia by individual conidiophores of Blumeria graminis f. sp. hordei on barley leaves by digital microscopic techniques with electrostatic micromanipulation. Mycol. Res., 110, 18-27. http://dx.doi.org/10.1016/j.mycres.2005.09.007

Murai, T. (1991). Rearing method for clones of some aphids on tick bean, Vicia faba. Bull. Shimane Agric. Exp. Stat., 25, 78-82 (in Japanese with English summary).

Murai, T., \& Loomans, A. J. M. (2001). Evaluation of an improved method for mass-rearing of thrips and a thrips parasitoid. Entomol. Exp. Appl., 101, 281-289. http://dx.doi.org/10.1046/j.1570-7458.2001.00913.x

Nonomura, T., Matsuda, Y., Bingo, M., Onishi, M., Matsuda, K., Harada, S., \& Toyoda, H. (2001). Algicidal effect of 3-(3-indolyl)butanoic acid, a control agent of the bacterial wilt pathogen, Ralstonia solanacearum. Crop Prot., 20, 935-939. 
Nonomura, T., Matsuda, Y., Kakutani, K., Takikawa, Y., \& Toyoda, H. (2008). Physical control of powdery mildew (Oidium neolycopersici) on tomato leaves by exposure to corona discharge. Can. J. Plant Pathol., 30, 517-524. http://dx.doi.org/10.1080/07060660809507551

Nonomura, T., Matsuda, Y., Xu, L., Kakutani, K., Takikawa, Y., \& Toyoda, H. (2009). Collection of highly germinative pseudochain conidia of Oidium neolycopersici from conidiophores by electrostatic attraction. Mycol. Res., 113, 364-372. http://dx.doi.org/10.1016/j.mycres.2008.11.012

Shimizu, K., Matsuda, Y., Nonomura, T., Ikeda, H., Tamura, N., Kusakari, S., Kimbara, J., \& Toyoda, H. (2007). Dual protection of hydroponic tomatoes from rhizosphere pathogens Ralstonia solanacearum and Fusarium oxysporum f. sp. radicis-lycopersici and airborne conidia of Oidium neolycopersici with an ozone-generative electrostatic spore precipitator. Plant Pathol., 56, 987-997. http://dx.doi.org/10.1111/j.1365-3059.2007.01681.x

Tanaka, N., Matsuda, Y., Kato, E., Kokabe, K., Furukawa, T., Nonomura, T., Honda, K., Kusakari, S., Imura, T., Kimbara, J., \& Toyoda, H. (2008). An electric dipolar screen with oppositely polarized insulators for excluding whiteflies from greenhouses. Crop Prot., 27, 215-221. http://dx.doi.org/10.1016/j.cropro.2007.05.009

Taylor, R. A. J., Shalhevet, S., Spharim, I., Berlinger, M. J., \& Lebiush-Mordechi, S. (2001). Economic evaluation of insect-proof screens for preventing tomato yellow leaf curl virus of tomatoes in Israel. Crop Prot., 20, 561-569.

Teitel, M., Barak, M., Berlinger, M. J., \& Lebiush-Mordechai, S. (1999). Insect-proof screens in greenhouses: Their effect on roof ventilation and insect penetration. Acta Hort., 507, 25-34.

Weintraub, P. G., \& Berlinger, M. J. (2004). Physical Control in Greenhouses and Field Crops. in: Horowitz, A. R. \& Ishaaya, I. (eds.) Insect Pest Management, Springer-Verlag, Berlin. pp. 301-318.

Table 1. Percentage of insect adults (A) captured with the ICW of an electrostatic insect exclusion screen negatively charged with different voltages and captured insects (B) blown away from the ICW by a wind ( $7 \mathrm{~m}$ s-1) of a blower

\begin{tabular}{|c|c|c|c|c|c|c|c|c|c|c|c|c|}
\hline \multirow{2}{*}{$\begin{array}{l}\text { Insects } \\
\text { tested }\end{array}$} & & \multicolumn{11}{|c|}{ Voltages $(\mathrm{kV})$} \\
\hline & & 0.7 & 1.2 & 1.7 & 2.2 & 2.7 & 3.2 & 3.7 & 4.2 & 4.7 & 5.2 & 5.7 \\
\hline \multirow[t]{2}{*}{ Shore flies } & A & 0 & 0 & 0 & 0 & 0 & $51.7 \pm 5.8$ & $96.7 \pm 2.9$ & 100 & 100 & 100 & 100 \\
\hline & $\mathrm{B}$ & ${ }^{*}$ & - & & & - & $96.7 \pm 2.9$ & $3.3 \pm 2.9$ & 0 & 0 & 0 & 0 \\
\hline \multirow[t]{2}{*}{ Thrips } & A & 0 & 0 & 0 & 0 & 0 & $80.0 \pm 5.0$ & $96.7 \pm 2.9$ & 100 & 100 & 100 & 100 \\
\hline & B & - & - & & & & 100 & $83.3 \pm 5.8$ & 0 & 0 & 0 & 0 \\
\hline \multirow[t]{2}{*}{ Aphids } & A & 0 & 0 & $46.7 \pm 5.8$ & $93.3 \pm 7.6$ & 100 & 100 & 100 & 100 & 100 & 100 & 100 \\
\hline & $\mathrm{B}$ & - & - & $75.0 \pm 5.0$ & 0 & 0 & 0 & 0 & 0 & 0 & 0 & 0 \\
\hline \multirow[t]{2}{*}{ Whiteflies } & A & 0 & 0 & $35.0 \pm 8.7$ & $81.7 \pm 7.6$ & $96.7 \pm 2.9$ & 100 & 100 & 100 & 100 & 100 & 100 \\
\hline & $\mathrm{B}$ & - & & 100 & $78.3 \pm 12.6$ & $3.3 \pm 5.8$ & 0 & 0 & 0 & 0 & 0 & 0 \\
\hline
\end{tabular}

*, , no insect to be blown. 
Table 2. Appearance of powdery mildew colonies on leaves of hydroponic tomatoes grown in a halved greenhouse

\begin{tabular}{cccccc}
\hline \multirow{2}{*}{ Experiments } & \multirow{2}{*}{$\begin{array}{c}\text { Parts of } \\
\text { greenhouse }\end{array}$} & \multicolumn{2}{c}{ Total number of colonies counted at 10-day } & \multirow{2}{*}{$\begin{array}{c}\text { Percentage of } \\
\text { intervals }\end{array}$} \\
\cline { 3 - 6 } & infected plants \\
\cline { 3 - 6 } 1 & Non-charged & 104 & 225 & 274 & 52.1 \\
& Screen-charged & 0 & 0 & 0 & 0 \\
\hline \multirow{2}{*}{2} & Non-charged & 223 & 351 & 522 & 70.8 \\
& Screen-charged & 0 & 0 & 0 & 0 \\
\hline \multirow{2}{*}{3} & Non-charged & 110 & 211 & 223 & 77.1 \\
& Screen-charged & 0 & 0 & 0 & 0 \\
\hline
\end{tabular}

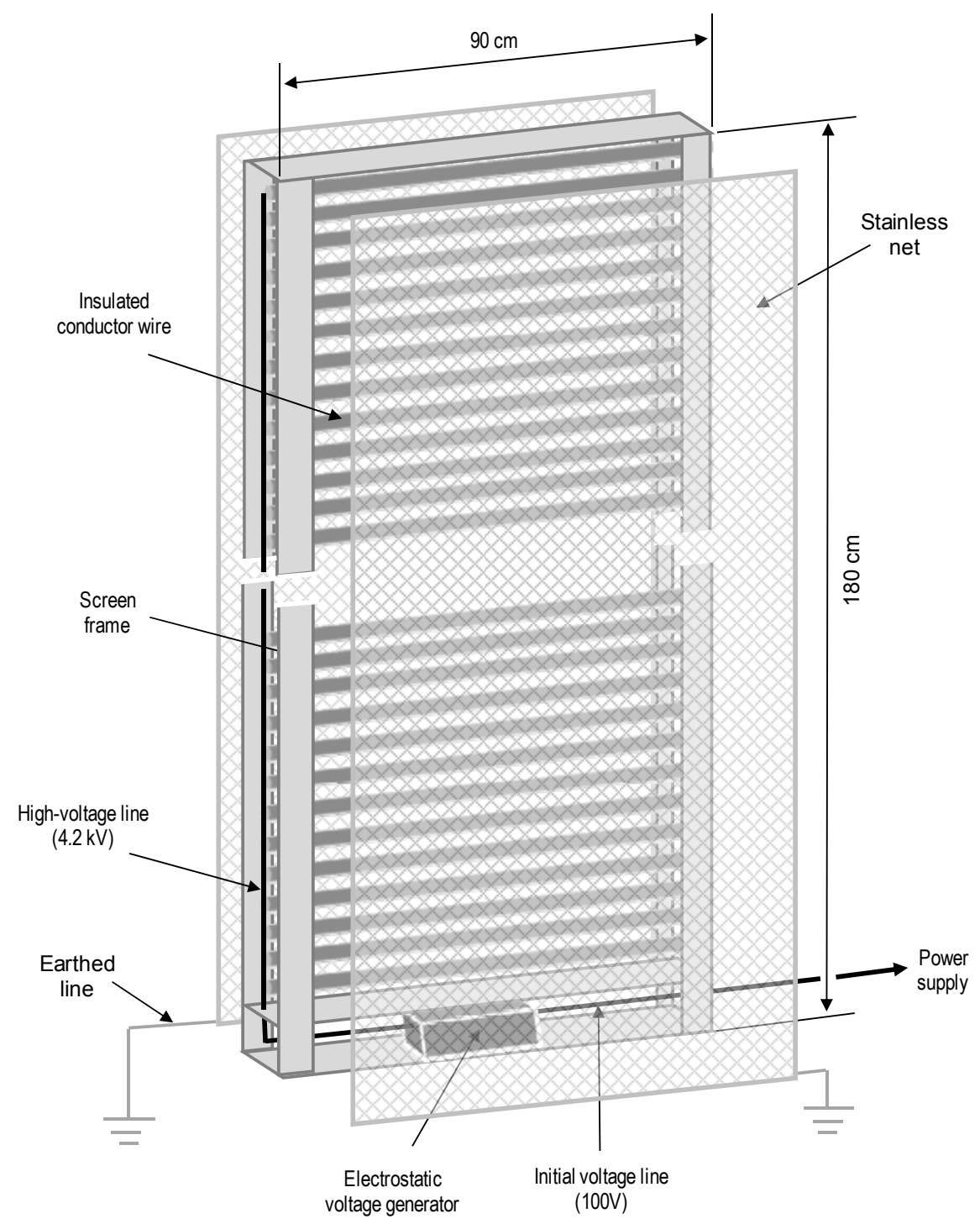

Figure 1. Diagram of a triple-layered electric field screen 

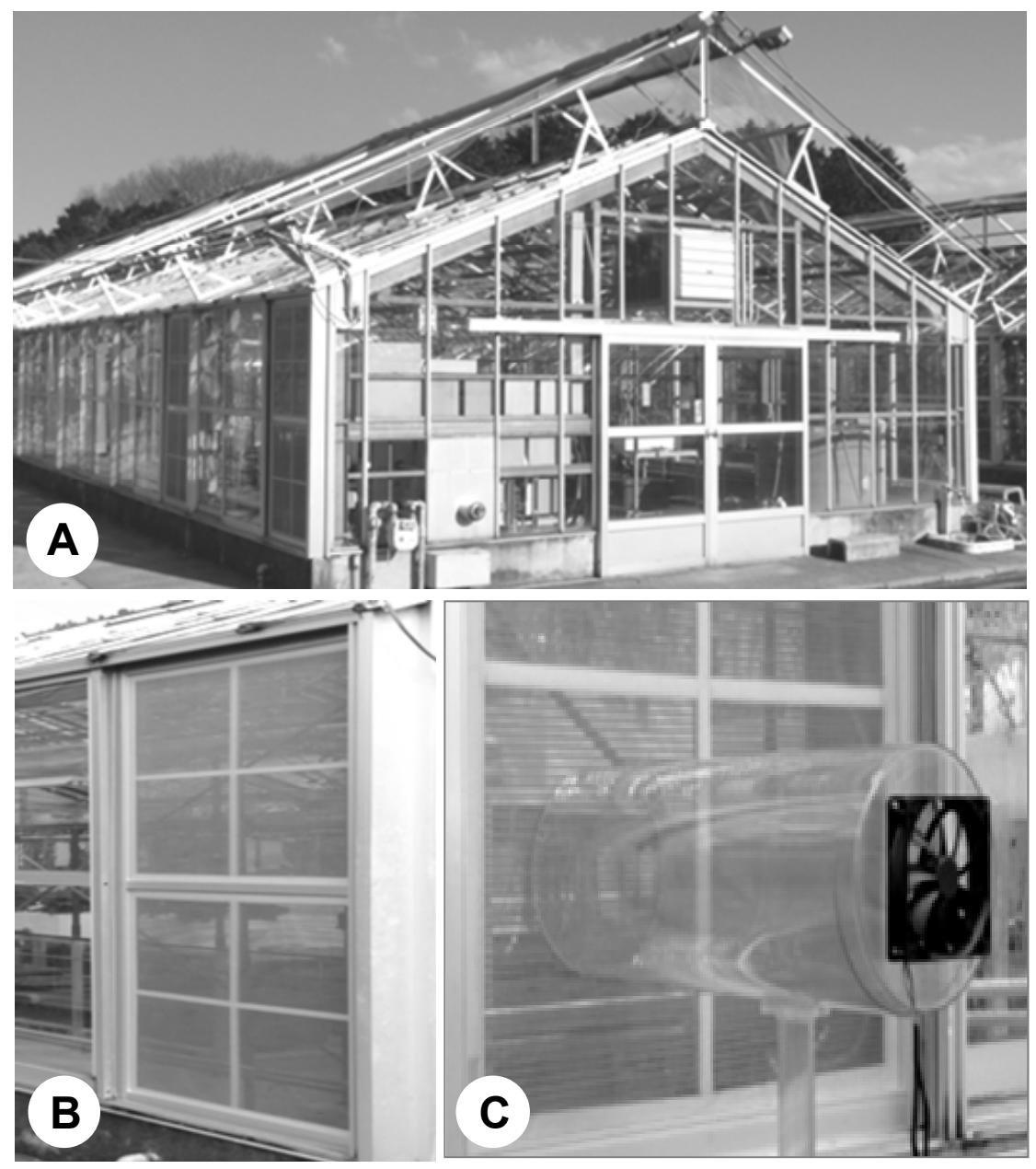

Figure 2. A greenhouse (A) used in the present study, an electric field screen installed on a lateral window (B) and a transparent acrylic cylinder with an electric fan used to test insect avoidance of the screen (C) 


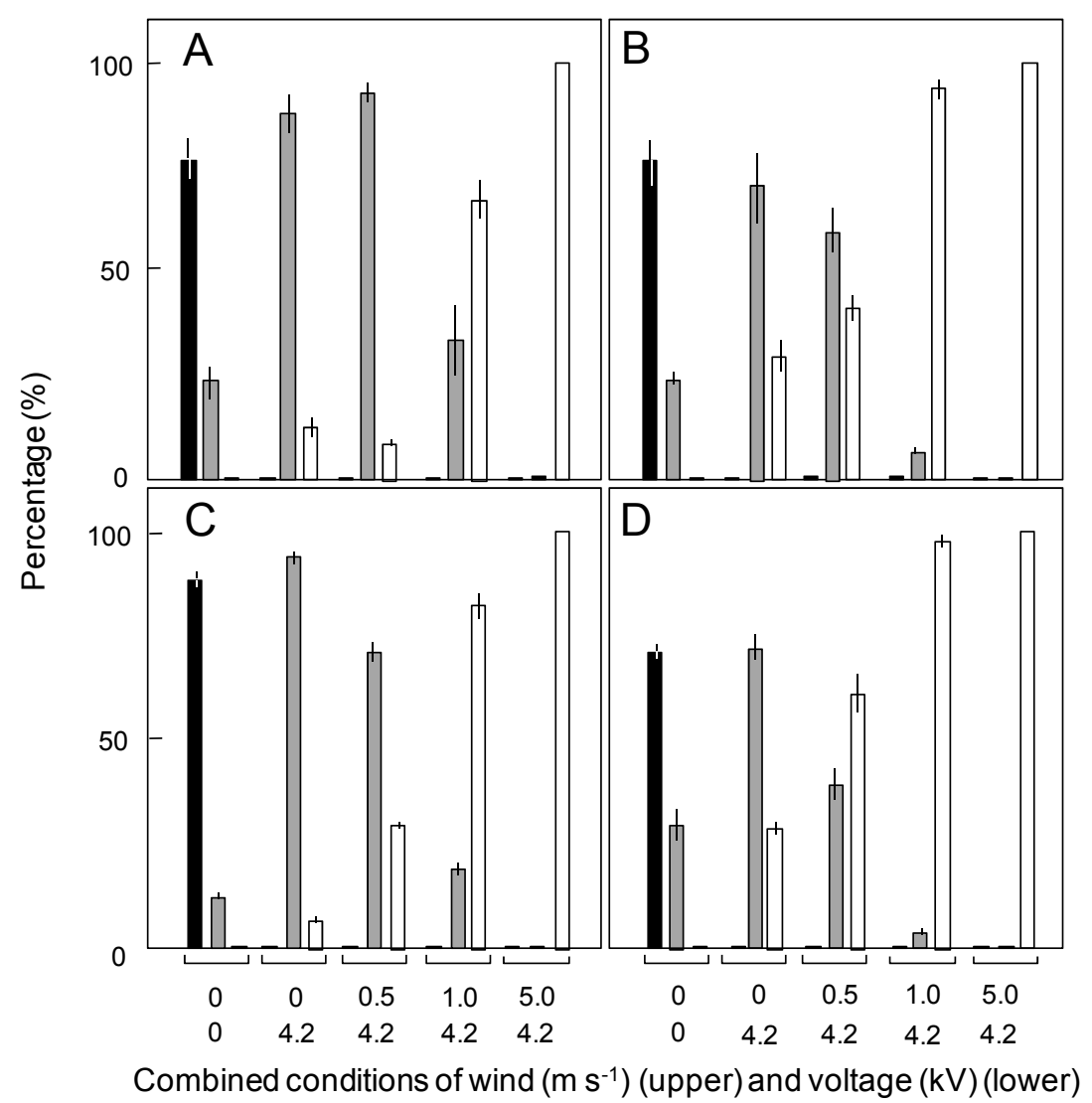

Figure 3. Behaviors by adults of shore flies (A), western flower thrips (B), green peach aphids $(\mathbf{C})$ and whiteflies

(D) reaching the screen net under different conditions of wind and voltage. Dark, gray and open columns represent the insects passing through the screen, removing without entering the screen, and being drawn to the ICW, respectively 